\title{
Investigation of the influence of operation conditions on the discharge of PCM ceiling panels.
}

\author{
José Quesada Allerhand, ${ }^{1 *}$, Ongun Berk Kazanci ${ }^{1}$, and Bjarne W. Olesen ${ }^{1}$ \\ ${ }^{1}$ International Centre for Indoor Environment and Energy, Department of Civil Engineering, Technical University of Denmark
}

\begin{abstract}
The aim of this study was to determine favorable operation conditions for ceiling panels containing phase change materials (PCM) for cooling applications in office rooms. A recently renovated room in the Technical University of Denmark was used to have realistic boundary conditions. Using TRNSYS 17, the performance of the PCM panels during the cooling season in passive operation, discharge by air, and discharge by water circulation were investigated. A set of simulations were performed during a representative week in the cooling period. The room was simulated with no climatic systems, PCM without active discharge, ventilation during occupied hours only, and PCM with ventilation during occupied hours. Afterwards, two discharge methods were investigated, night ventilation at different flow rates and water circulation in pipes embedded in the panels. A parametric analysis was performed to identify the influence of operation factors in the thermal environment of the room. The parameters studied were the water flow rate, supply water temperature and circulation schedule as well as the conductivity of the PCM. After selecting different operating conditions of the water discharge, simulations were performed from May to October to observe the performance of the selected operation conditions. The results show that the PCM is more effective to provide adequate indoor thermal conditions if it is discharged actively by means of water. The parameters that affect the thermal indoor environment the most are the water circulation schedule, the water supply temperature, and the PCM thermal conductivity. The water flow rate did not have a significant influence. The study shows the importance of selecting an appropriate operation and control strategy for the PCM system. The process used in the study can be potentially used as a procedure for the design of similar climatic systems to determine if active discharge of the PCM is needed and if yes, which discharge method is needed.
\end{abstract}

\section{Introduction}

Phase change materials (PCM) in building applications can improve building thermal performance for cooling applications. These materials store and release energy during a change of phase, for example from solid to liquid and provide numerous advantages in terms of thermal comfort and energy performance of buildings. These include more stable indoor temperatures and reduction of peak loads, as these materials have a similar effect to using high thermal mass in buildings [1]. The different studies dealing with PCMs in building applications have studied the material in two general ways. In the first approach, the material is added into a building element, for example a wall, increasing the thermal mass of the construction. The second approach deals with influencing the storage or release of the energy in the PCM [2]. The strategies that have been studied to do this are mainly using night ventilation, which can be natural or mechanical, or circulating water through pipes embedded in the material itself or close to it [3] [4] [5] [6] [7]. In cooling applications, the goal is to discharge the stored energy, usually during an unoccupied period so that the material can store the cooling loads of the next day.

In this study, the focus was on the operation of PCM incorporated in ceiling panels in an office room. The PCM in this concept is discharged by circulating water through pipes embedded inside the ceiling panels. Through numerical methods using TRNSYS 17, a recently renovated room in the Technical University of Denmark was simulated with the mentioned ceiling panels. The goal of the study was to identify the influence of different operation parameters in the thermal environment of the room. 


\section{Methodology}

An existing room in the Technical University of Denmark was modelled in TRNSYS 17. The room's properties are shown in Table 1. The room's west wall faces to the outside. This wall consist of two layers of brick with no insulation between them. The glazing elements consist of two pane windows. The considered U-Value of the wall was $2.3 \mathrm{~W} / \mathrm{m}^{2} \mathrm{~K}$ while the considered properties of the window were $2.8 / 0.75 / 0.82(\mathrm{U} / \mathrm{g} / \mathrm{LT})$. The room was simulated with 24 occupants in a considered schedule from 8:00 to 17:00 with a mid-day break [8].

Table 1:Room geometric parameters and heat gains

\begin{tabular}{|l|l|l|}
\hline Room parameters & & \\
\hline Orientation & West & \\
\hline Height & 2.9 & $\mathrm{~m}$ \\
\hline Length & 8.8 & $\mathrm{~m}$ \\
\hline Width & 5.8 & $\mathrm{~m}$ \\
\hline Plenum height & 0.5 & $\mathrm{~m}$ \\
\hline Area & 51 & $\mathrm{~m}^{2}$ \\
\hline Volume & 148 & $\mathrm{~m}^{3}$ \\
\hline Total window area & 7.38 & $\mathrm{~m}^{2}$ \\
\hline Occupant gains & 35 & $\mathrm{~W} / \mathrm{m}^{2}$ \\
\hline Equipment gains & 32 & $\mathrm{~W} / \mathrm{m}^{2}$ \\
\hline Lighting & 10 & $\mathrm{~W} / \mathrm{m}^{2}$ \\
\hline Total internal heat gains & 77 & $\mathrm{~W} / \mathrm{m}^{2}$ \\
\hline
\end{tabular}

A TMY-2 weather file for Copenhagen was used for the simulations. The cooling season was considered from April 30 to October 01 . The cooling and heating demand to maintain the room operative temperature between 20 and 26 ${ }^{\circ} \mathrm{C}$ is shown in Fig. 1 .

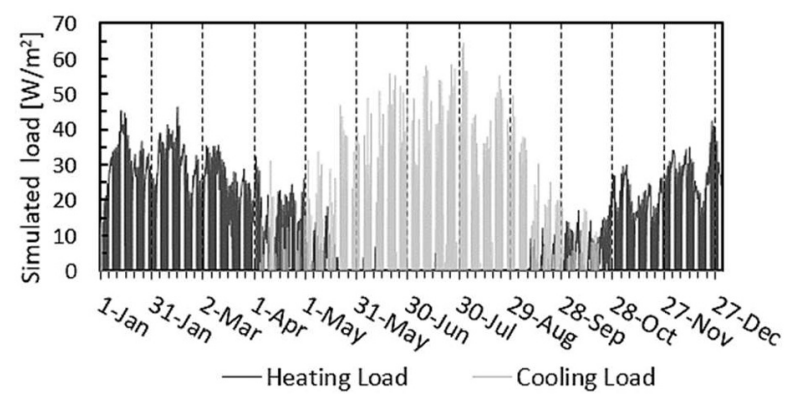

Fig 1. Simulated room heating and cooling demand.

The thermal environment assessment was performed with the operative temperature classification suggested in prEN-16798 [8]. This categorization works around an optimal temperature of $24.5^{\circ} \mathrm{C}$. In Category $\mathrm{I}$, the room temperature is maintained in a range of $24.5{ }^{\circ} \mathrm{C} \pm 1 \mathrm{~K}$. In Category II and III this range is $\pm 1.5 \mathrm{~K}$ and $\pm 2.5 \mathrm{~K}$, respectively. Temperatures outside these ranges are defined as outside of category.

A commercially available PCM (Rubitherm R24) is poured into a steel casing, which works as a panel which is then installed in the suspended ceiling of the room. The panels are $60 \mathrm{~cm} \times 60 \mathrm{~cm}$ and have a total thickness of $3 \mathrm{~cm}$. The panels contain copper pipes that can be used for water circulation. The pipes are incorporated into an aluminum structure that provides stability and could potentially improve the heat transfer of the panel. The working principle is that the PCM will store the heat gains during the day as it melts. After the occupants leave the room, the stored energy in the PCM has to be discharged, so that the panel can absorb the heat gains of the following day. Table 3 shows a summary of the main material properties obtained from the manufacturer [9].

Table 3. Properties of the PCM used

\begin{tabular}{|l|l|l|}
\hline Melting Range & $21-25$ & ${ }^{\circ} \mathrm{C}$ \\
\hline Freezing range & $25-21$ & ${ }^{\circ} \mathrm{C}$ \\
\hline Heat storage capacity & 160 & $\mathrm{~kJ} / \mathrm{kg}$ \\
\hline Specific heat capacity & 2 & $\mathrm{~kJ} / \mathrm{kg}$ \\
\hline Density solid & 880 & $\mathrm{~kg} / \mathrm{m}^{3}$ \\
\hline Density liquid & 770 & $\mathrm{~kg} / \mathrm{m}^{3}$ \\
\hline Heat conductivity & 0.2 & $\mathrm{~W} / \mathrm{mK}$ \\
\hline
\end{tabular}

The amount of PCM used for the system was decided by considering the real boundaries of the room and the panel. Regarding the room, $50 \%$ of the ceiling area was selected to arrange PCM panels based on the room's boundary conditions. In a thickness of $2 \mathrm{~cm}$, and $50 \%$ ceiling coverage, $40 \mathrm{~W} / \mathrm{m}^{2}$ can be stored in the PCM.

To model the PCM panel, TRNSYS component type 399 was used. This is a validated component that simulates PCM embedded in walls with the addition of embedded pipes. [10]. The PCM panel was modelled as a single layer of PCM in the component. The density of the PCM used was the average between the density of the liquid and the solid states $\left(825 \mathrm{~kg} / \mathrm{m}^{3}\right)$. The melting and freezing curves provided by the PCM manufacturer were used for the enthalpytemperature functions required as input for Type 399 [9][10].

A first group of simulations was performed to observe the effects of passive climatic control by adding PCM in the room. The room was simulated under the four different scenarios shown in Table 4 . In the first scenario, named Case-1, the room was simulated without any climatic systems and without PCM. The only airflow in case 1 is the infiltration. The second scenario, named Case- 2 consist of the room modeled with the PCM incorporated in the ceiling. No action to actively influence the temperature of the material was simulated and in the same way as Case-1, the only airflow was the infiltration flow. The third scenario, Case-3, consist of adding an air flow during occupied hours provided by a ventilation system to the room without PCM. The modelled flow rate corresponds to the required ventilation flow rate indicated in [8] and is supplied at a constant temperature of $20{ }^{\circ} \mathrm{C}$. Finally the last scenario simulated, Case-4, consist of adding PCM in the room's ceiling, like in Case-2 and including the ventilation air flow rate, as in Case-3. 
After performing these simulations, a preliminary assessment scenario was simulated in which water was circulated in the PCM panels in the scenarios that have PCM (Case-2) and (Case-4). The conditions for the operation of the water selected were a mass flow rate of $326 \mathrm{~kg} / \mathrm{h}$, supply temperature of $18{ }^{\circ} \mathrm{C}$ and operation schedule from 23:00 to 05:00.

Table 4. Simulated scenarios of the room

\begin{tabular}{|l|l|l|l|l|}
\hline & Case 1 & Case 2 & Case 3 & Case 4 \\
\hline PCM & no & yes & no & yes \\
\hline CAV. Vent & no & no & yes & yes \\
\hline
\end{tabular}

A parametric study was then performed in TRNSYS 17 with different operation conditions. The PCM was discharged by two different methods, circulating water in the ceiling panels and by air using the ventilation system during the night to cool the room. In the former case, the conductivity of the PCM, the water flow rate, temperature, and operation schedule were varied. In the latter case, the PCM conductivity and the air flow rate were varied. The parametric study can be seen summarized in Fig. 3 and Fig.4

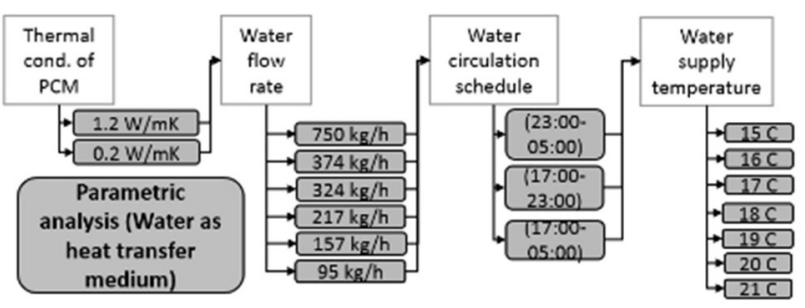

Fig. 3: Water parametric study

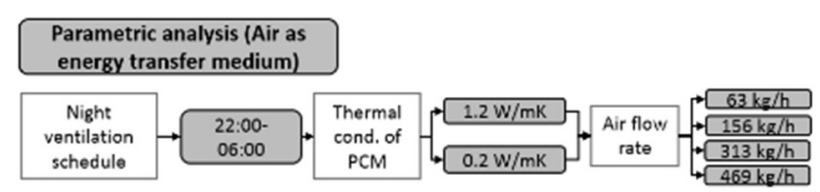

Fig. 4: Air parametric study

In this study, it was decided to focus on the water discharge operation in more detail. From the parametric study using water as the heat transfer medium, seven cases were selected and simulated during the entire cooling season. The selected cases are shown in Table 5.
Table 5: Selected system operation types to study during the cooling season

\begin{tabular}{|l|l|l|l|l|}
\hline & $\begin{array}{l}\text { Water Circ. } \\
\text { Schedule }\end{array}$ & $\begin{array}{l}\text { Water } \\
\text { temp. }\end{array}$ & $\begin{array}{l}\text { Water } \\
\text { flow rate }\end{array}$ & $\begin{array}{l}\text { PCM } \\
\text { thermal } \\
\text { cond. }\end{array}$ \\
\hline & & {$\left[{ }^{\circ} \mathrm{C}\right]$} & {$[\mathrm{kg} / \mathrm{h}]$} & {$[\mathrm{W} / \mathrm{mK}]$} \\
\hline Type 1 & $17: 00-05: 00$ & 15 & 157 & 0.2 \\
\hline Type 2 & $17: 00-05: 00$ & 18 & 374 & 0.2 \\
\hline Type 3 & $23: 00-05: 00$ & 18 & 374 & 0.2 \\
\hline Type 4 & $17: 00-05: 00$ & 15 & 374 & 1.2 \\
\hline Type 5 & $17: 00-05: 00$ & 18 & 326 & 1.2 \\
\hline Type 6 & $23: 00-05: 00$ & 18 & 374 & 1.2 \\
\hline Type 7 & $23: 00-05: 00$ & 15 & 374 & 1.2 \\
\hline
\end{tabular}

The influence of a controller based on the room's operative temperature was also studied. This control condition interrupts the water flow rate if the room's operative temperature is lower than $23{ }^{\circ} \mathrm{C}$. The seven selected cases were simulated in the cooling season with this control condition.

\section{Results}

Fig.5 shows the thermal comfort categories during the cooling season (30 April to 01 October). Case-1, has the most percentage of occupied time outside Category III, followed by Case-2, Case- 3 and Case- 4 . Case- 3 (using ventilation without PCM) reduced the percentage of the occupied period outside Category III from $66 \%$ to $22 \%$, while Case-2, (adding PCM without ventilation) reduced this percentage marginally (from $66 \%$ to $64 \%$ ). The best thermal environment was observed in Case-4, where PCM with the CAV ventilation were simulated.

Fig. 6 shows the room operative temperature, and state of the phase of the PCM in two scenarios. The first scenario is PCM with no water circulation, in passive operation. The second scenario is the PCM with water circulation at $18{ }^{\circ} \mathrm{C}$ from 23:00 to 05:00. No ventilation was simulated in any case. The room's operative temperature without any systems is shown as well. Circulating water in the panels during the night increases the solidification percentage of the material and a reduction in the room's operative temperature. In the case where no water is circulated, the PCM remains at a liquid state and the room operative temperature starts to be the same as the operative temperature with no systems. 


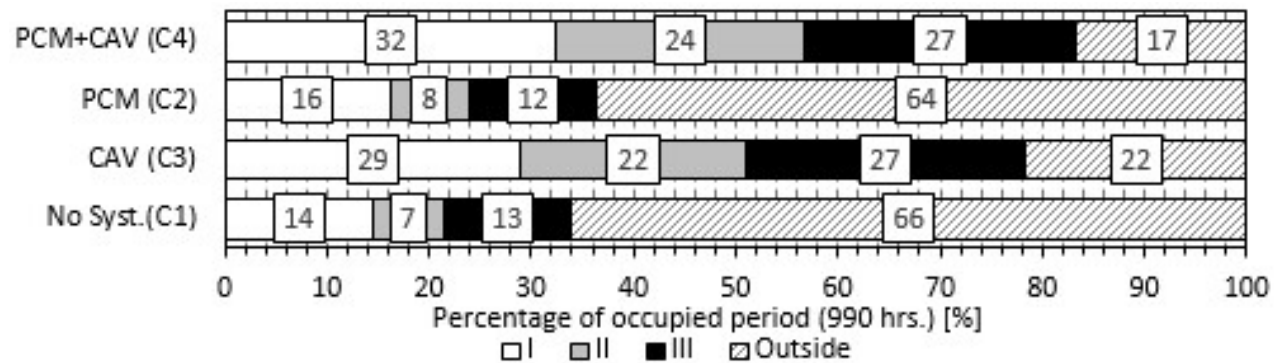

Fig. 5. Thermal environment classification during occupied period of cooling season for different climatic systems

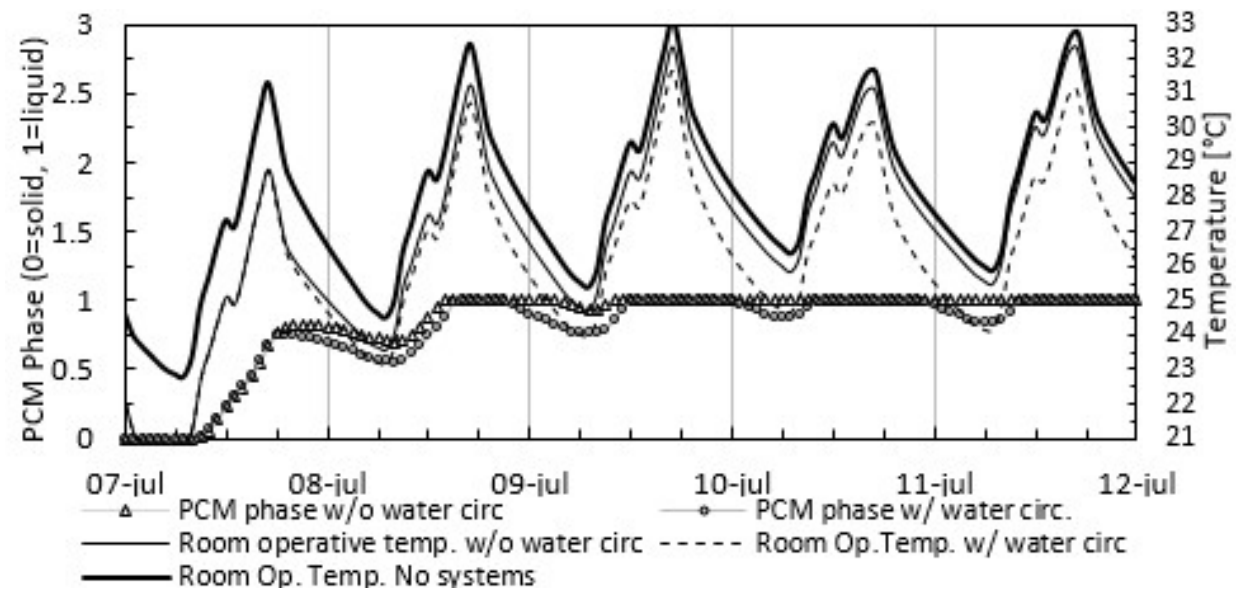

Fig. 6. PCM,phase and room operative temperature for case 2 with and without water circulation in PCM during one summer week.

Fig.7 shows the time within Category II for the different simulations performed by discharging the PCM with air or water. The most amount of time within this category was achieved by a case using water as discharge.

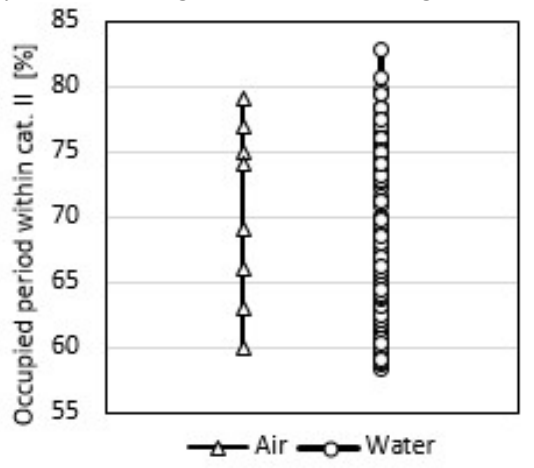

Fig. 7. Percentage of occupied period within Cat. II during one week by discharging the PCM with water or air.

Fig.8 shows the percentage of occupied hours within Category II within 5 working days under different operating conditions of the PCM system. In general, more time within Category II is achieved by decreasing the water supply temperature, circulating water for a longer period, increasing the conductivity, and by increasing the flow rate. In most cases, it can be seen that the increase in flow rate has only marginal effects in the thermal environment.

Fig.9 shows the solidification percentage of the PCM in three July days under different operations. In chart a), water supply temperature is varied during a 6-hour circulation schedule. In chart b), the water supply temperature is varied during a 12-hour circulation schedule. In chart c), three different water circulation schedules are simulated with constant flow rate and water supply temperature. Chart d) and e) are simulations with different PCM conductivities. The difference between these charts are the water circulation schedule, supply temperature, and flow rate. Finally, chart f) is a variation of the flow rate with the rest of parameters constant. Generally, the lower supply temperature and longer circulation schedule increase the solidification percentage of the PCM. 


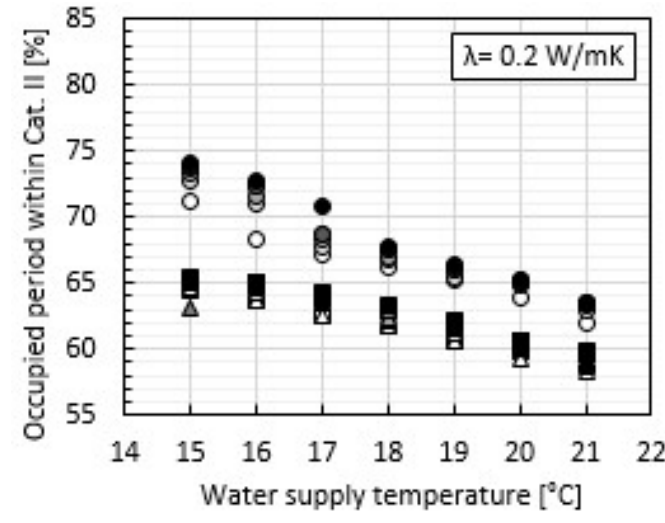

$017: 00-05: 00 \mathrm{~m}=95 \mathrm{~kg} / \mathrm{h}$ $017: 00-05: 00 \mathrm{~m}=157 \mathrm{~kg} / \mathrm{h}$ $017: 00-05: 00 \mathrm{~m}=217 \mathrm{~kg} / \mathrm{h}$ $017: 00-05: 00, m=326 \mathrm{~kg} / \mathrm{h}$ $017: 00-05: 00, m=374 \mathrm{~kg} / \mathrm{h}$ -17:00-05:00, m=750 kg/h

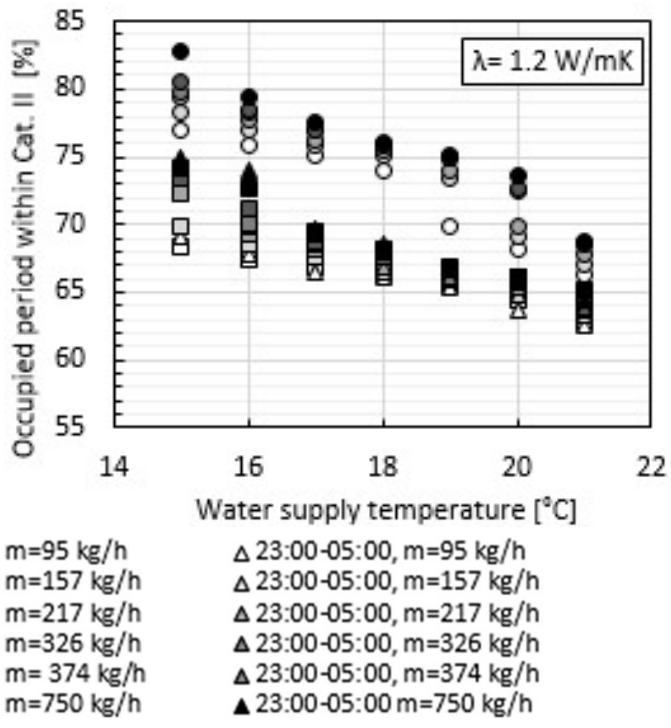

ㅁ 17:00-23:00, m=95 kg/h 口 17:00-23:00, m=157 kg/h 17:00-23:00, $\mathrm{m}=217 \mathrm{~kg} / \mathrm{h}$ $\square$ 17:00-23:00, m=326 kg/h 17:00-23:00, $m=374 \mathrm{~kg} / \mathrm{h}$ - 17:00-23:00, m=750 kg/h

Fig. 8. Occupied period within Cat. II from 07 July to 12 July under different operating conditions.

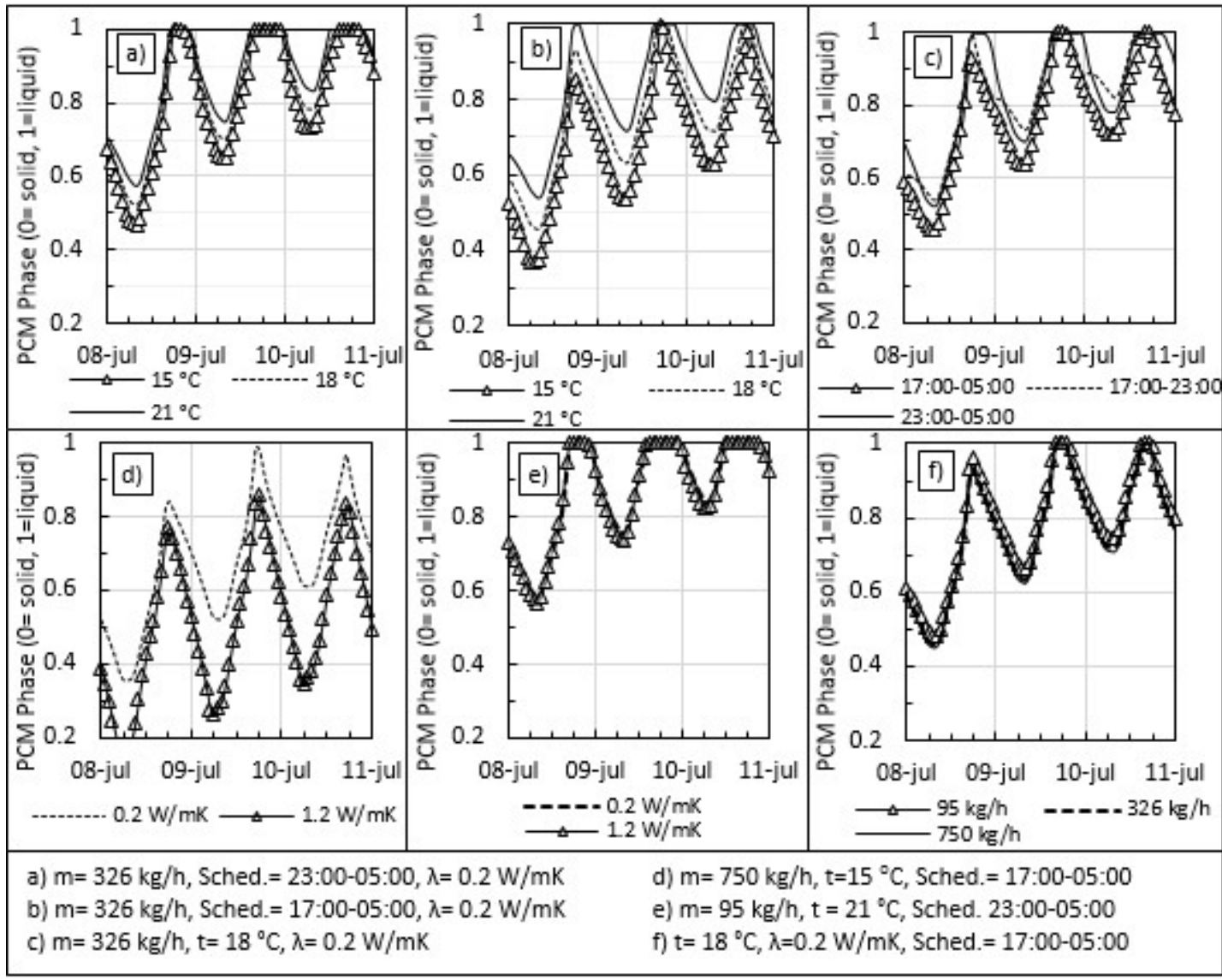

Fig 9. PCM solidification in three July days for different operation conditions. 


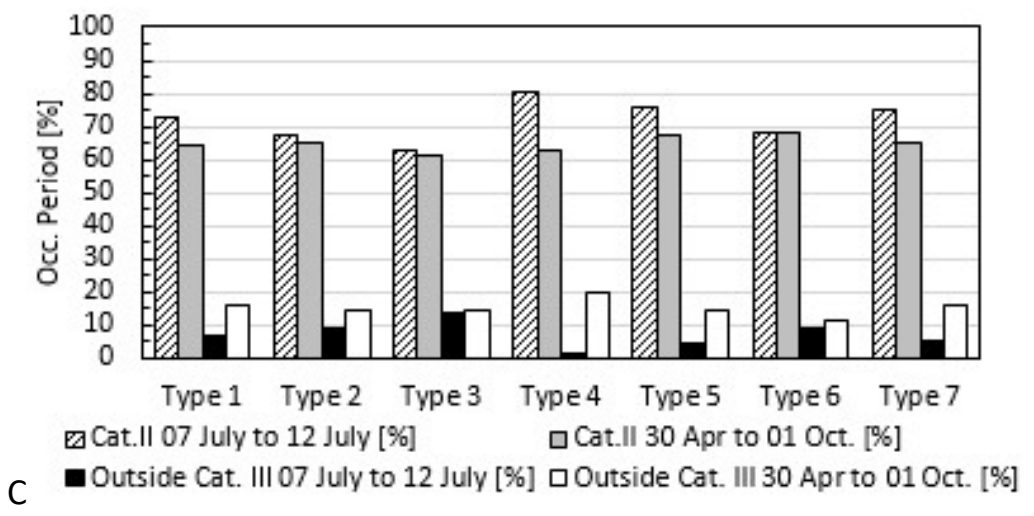

Fig. 10. Comparison of thermal environment for selected cases between one summer week and the whole cooling period (30 April to 01 October) simulations.

Fig. 10 shows the thermal environment of seven selected operating modes using water to discharge the PCM during a one-week simulation and a simulation that covers the entire cooling period (May to October). Extending the simulation period to the cooling season led to changes in the thermal environment results. In general, the time within Category II decreased and the time outside Category III increased. Some of the tendencies observed in the parametric study during one week also changed. In the one week simulation period, the system performed best in terms of thermal environment with higher conductivity, longer water circulation schedules, higher flow rate and lower supply water temperature. In Fig.10, type 6 outperforms types 4 and 5, which have longer water circulation periods and is now the operation type that results with higher percentage within Category II, when in the one week simulation it was the type with less percentage of time within this category.

Fig. 11 shows the thermal environment obtained under system operation types 1 to 7 with the addition of a control condition to prevent over cooling. With this control, the flow into the PCM panels will stop if the room's operative temperature drops below $23^{\circ} \mathrm{C}$. With this control condition,

\section{Discussion}

The results shown in Fig. 5 show that adding PCM improves the thermal environment, but only marginally. Adding only ventilation to the base case had a much larger effect on the improvement of the thermal environment of the room than adding PCM only. The reason for this can be the lack of solidification in the PCM during the unoccupied periods. To increase the solidification rate during the night, the PCM has to be actively controlled such as in studies performed in [3] and [4]. Water and air were used for these purposes. The studies of [4] and [11] both reached the conclusion that the PCM improves thermal comfort more effectively when it is actively discharged. In these studies, this active discharge the operation types that result in the best thermal environment are the systems with longer water circulation schedules and high conductivity (Types 4 and 5) and the same trends observed during the one week simulations are maintained.

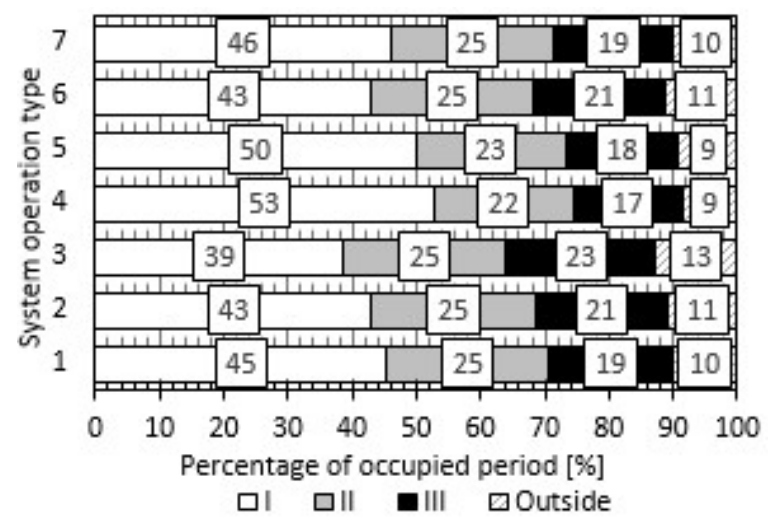

Fig. 11. Thermal environment of system types 1 to 7 with control to prevent over cooling.

was made by venting the rooms during the night. The rest of the results supports this idea.

Fig.6 confirms that, as expected, circulating water during the night increases the solidification percentage of the PCM. The room operative temperature is also lower than when water is not circulated. If water is not circulated during the night, including PCM decreased the room's temperature, but the effect is reduced each day. This is a first indication that an active discharge of the material is necessary and the active discharge results in a better thermal environment.

The parametric study of a week in July showed that in general, a combination between a high conductivity in the material, low supply water temperature in the panels, and longer circulation time resulted in a better thermal environment. Not all of the studied parameters had the same 
effect in the results. Individually, the water supply temperature and the water circulation schedule are the parameters which had the most influence in the operation of the PCM. Increasing the material conductivity leads to a better thermal environment in the room, but only if the rest of operation conditions are favorable. A relationship can be observed between the thermal environment of the room and the solidification percentage of the PCM. The conditions that create better thermal environment in Fig. 8 create an increased solidification percentage in Fig.9.

The results agree well with conclusions from the work of [1]. The authors state that water inlet temperature, operation schedule, and PCM thermal conductivity as parameters that significantly influence a room's thermal environment. The relationships between the variation of these parameters and the resulting thermal environment performed in this study agree with the work of the authors.

The possibility of discharging the PCM with outside air was also briefly investigated. It was interesting to observe that almost the same range of comfort conditions was achieved by the air discharge and the water discharge. These results should be studied further before definitive conclusions can be drawn. Potentially, night ventilation might result in higher energy use due to the energy use of the fans required to circulate outdoor air. An alternative to achieve higher energy savings could be to evaluate the discharge of the PCM using natural ventilation during the night. It can be interesting to study how either lower flow rates when relying on buoyancy driven ventilation or variability of conditions when relying in pressure driven ventilation affect the thermal environment. The brief study performed with outside air shows reasonable justification to perform further studies using a similar strategy, as the climate of Copenhagen seems adequate for this.

The thermal environment results changed considerably when extending the simulation period from a coolingdominated week to the entire cooling season (which includes a certain heating demand in the transition periods). This is because the simulation during the cooling season includes months in which there is a mixed heating and cooling demand. To prevent overcooling, a control condition that interrupts the water circulation if the room temperature is lower than $23{ }^{\circ} \mathrm{C}$ was added. With this control condition, the same relationships between the system's operation parameters and the resulting thermal environment observed in the one week simulation parametric analysis are repeated.

It is important to note that the simulations performed represented one phase change material in a specific room, with specific loads and a specific climate context. Although the thermal categories used are a good indicator of thermal comfort, certain assumptions were made to simplify thermal comfort only to operative temperatures. The assumptions of air velocity, and constant clothing level of occupants might vary considerably from a controlled test or a simulation test than in a real application.

\section{Conclusion}

This study investigated different operation conditions of active PCM systems and their effects on PCM behavior and thermal indoor environment. In order for the systems to be effective, the cycle of melting and solidification has to be completed as much as possible. Under high cooling loads, this cycle should be optimized by using an active method. In the case of using water for this purpose, a combination between lower supply temperature and longer circulation schedule will result in better thermal environment. The study also shows how simulation tools can aid in the design of these systems.

This study was financially supported by the European Union's Horizon 2020 research and innovation programme under grant agreement No. 723649 and by the International Centre for Indoor Environment and Energy (ICIEE), Technical University of Denmark (DTU).

\section{References}

[1] C. Tzivanidis, K. A. Antonopoulos, and E. D. Kravvaritis, Int. J. ENERGY Res.36 18-35 (2012).

[2] H. Akeiber et al., Renew. Sustain. Energy Rev. 60, 1470-1497 (2016).

[3] M. Koschenz and B. Lehmann, Energy Build. 36 567-578 (2004).

[4] M. Alam, J. Sanjayan, P. X. W. Zou, S. Ramakrishnan, and J. Wilson, Energy Build,, vol. 148 238-256 (2017).

[5] H. Farhan, E. Bourdakis, B. W. Olesen, C. Stefansen, and O. B. Kazanci, in ASHRAE Winter Conference, (2018).

[6] L. Flemming Nielsen, E. Bourdakis, O. B. Kazanci , and B. W. Olesen, ASHRAE Winter Conference, (2018).

[7] E. Bourdakis, O.B. Kazanci, F. Grossule and B. W. Olesen, ASHRAE Annual Conference, (2016).

[8] CEN, EN 16798-1, (2016).

[9] Rubitherm R24. [Online]. https://www.rubitherm.eu/media/products/datashee ts (Accessed: 03-Dec-2018).

[10] Dentel, Arno et al..TRNSYS TYPE 399 http://www.trnsys.de/download/de/ts_type_399_en .pdf. (accessed: 01.05.2018).

[11] H. Jamil, M. Alam, J. Sanjayan, and J. Wilson, Energy Build.,133, 217-229, (2016). 